\title{
Patología médica y embarazo. Trastornos gastrointestinales, neurológicos, cardiovasculares y dermatológicos
}

\section{Medical disorders and pregnancy. Gastrointestinal, neurological, cardiovascular and dermatological disorders}

\author{
A.F. Pérez Rodríguez, M. Roche, C. Larrañaga
}

\section{RESUMEN}

En la mujer embarazada se pueden presentar patologías médicas similares a la no gestante, si bien el cuadro clínico de algunas patologías así como el proceso diagnóstico o terapéutico puede estar alterado por los cambios que el embarazo produce en ella, así como por la presencia del feto, que en algunos casos puede limitar los métodos diagnósticos o las terapias a aplicar. En este trabajo se exponen las patologías digestivas, cardiovasculares, del sistema nervioso y dermatosis más relevantes por su frecuencia o por su gravedad, que pueden presentarse en una consulta de urgencias, con un enfoque práctico sobre el manejo inicial y sobre el pronóstico para la madre y el feto.

Palabras clave. Embarazo. Enfermedades cardiovasculares. Enfermedades gastrointestinales. Dermatopatías. Enfermedades del sistema nervioso.

\begin{abstract}
A pregnant woman can present medical pathologies similar to a woman who is not pregnant. However, the clinical features of some pathologies and the diagnostic or therapeutic process might be altered due to changes produced by pregnancy and the presence of the foetus. In some cases this can limit the diagnostic methods or the therapies to be applied. This article sets out the digestive and cardiovascular pathologies, pathologies of the nervous system and dermatoses of greatest relevance due to their frequency or severity, which might be encountered in an emergency consultation. It also offers a practical approach for the initial handling and the prognosis for the mother and the foetus.
\end{abstract}

Key words. Pregnancy. Cardiovascular diseases. Gastrointestinal diseases. Dermatoses. Diseases of the nervous system.
Servicio de Obstetricia y Ginecología. Hospital. Virgen del Camino. Pamplona

\section{Correspondencia:}

Ana Felicitas Pérez Rodríguez

Bardenas Reales, 54, 4 A

31621 Sarriguren (Navarra)

Tfno. 636100483

E-mail: ana.perez.rodriguez@cfnavarra.es 


\section{INTRODUCCIÓN}

La gestación es un proceso fisiológico con posibles complicaciones. Durante el embarazo y puerperio, madre y feto se exponen a situaciones que pueden determinar el futuro de ambos.

Las complicaciones médicas en el embarazo son únicas por dos razones: primero, los cambios fisiológicos asociados al embarazo pueden afectar al curso y manifestaciones de las enfermedades, y segundo, la presencia del feto tiene un riesgo adicional así como una relación significativa con el tipo de fármacos que pueden ser prescritos.

\section{APARATO GASTROINTESTINAL. VÓMITOS. HIPEREMESIS GRAVÍDICA}

Cuando una gestante acude a urgencias por vómitos el primer paso es establecer si tienen causa gravídica o no. La emesishiperemesis gravídica tiene un diagnóstico por exclusión ${ }^{1}$.

Las semanas de gestación nos pueden orientar en el diagnóstico, ya que la emesis gravídica aparece a las 5-6 semanas, con clínica máxima a las 9 semanas y disminución hasta desaparecer a las 16-18 semanas, pero en $15-20 \%$ persisten hasta el $3^{\text {er }}$ trimestre, y $5 \%$ hasta el parto ${ }^{2}$. Las náuseas y vómitos que aparecen después de las 10 semanas es probable que no sean debidas a hiperemesis gravídica.

Las causas posibles de vómitos durante el embarazo son²:

- Relacionadas con la gestación: mola hidatiforme, embarazo múltiple, hidramnios, preeclampsia, inicio del trabajo de parto y reflujo gastroesofágico.

- No relacionadas con la gestación: apendicitis, gastroenteritis, colecistitis, pancreatitis, meningitis, pielonegritis y tumor cerebral.

\section{Diagnóstico}

El diagnóstico se realiza atendiendo a una serie de parámetros:

- Peso, TA ortostática, hemograma (hemoconcentración), ionograma (hiponatremia, hipocaliemia e hipoclore- mia), pruebas de coagulación, pruebas hepáticas (elevación en 15-25\%, 3-4 veces los niveles normales), renales (aumento de creatinina en casos severos) y pancreáticas (para descartar pancreatitis), hormonas tiroideas (descarta crisis hipertiroidea), sedimento urinario (cetonuria, aumento de la osmolaridad) ${ }^{2}$.

- Ecografía obstétrica para excluir enfermedad trofoblástica gestacional o embarazo múltiple.

- Ecografía abdominal para descartar enfermedad hepatobiliar.

- Fondo de ojo para descartar hipertensión intracraneal.

- La hiperemesis se describe objetivamente como los vómitos persistentes acompañados de pérdida de peso $>5 \%$ y cetonuria sin relación con otras causas $^{3}$ y que produce alcalosis metabólica hipoclorémica con hipopotasemia.

- Se debe ingresar a la gestante cuando haya intolerancia oral, pérdida de peso, signos de deshidratación con diuresis escasa o alteraciones de la analítica ${ }^{2}$.

\section{Tratamiento}

El tratamiento a administrar varía según la forma de presentación de la hiperemesis $^{3}$.

\section{- Formas leves o moderadas:} tratamiento ambulatorio

- Consejos higiénico-dietéticos: reposo, fraccionamiento de alimentos (comidas poco abundantes pero frecuentes), dieta rica en hidratos de carbono y pobre en grasas, mejor sólidos y fríos, evitar condimentos, bebidas con gas, tabaco, alcohol y olores fuertes. Apoyo psicológico. Informar sobre la evolución.

- Tratamiento farmacológico: cuando lo anterior no es suficiente.

1. Doxilamina+piridoxina vía oral $10-20$ mg c/8h (Cariban®).

2. Metoclopramida $10 \mathrm{mg}$ antes de cada comida (Primperan ${ }^{\circledR}$ ). 
- Tratamientos alternativos:

1. Jengibre $1 \mathrm{~g}$ al día durante 4 días.

2. Acupresión del punto P6 Neiguan ("muñequeras antimareo").

3. Acupuntura.

\section{- Formas graves o hiperemesis} gravídica: tratamiento hospitalario con ingreso

- Se prohibirán las visitas y se mantiene a la gestante en reposo a oscuras y a dieta absoluta. Si es necesario, dar apoyo psicológico.

- Control de constantes vitales, peso, diuresis y ionograma cada 24 horas.

- Tratamiento de la deshidratación, alteraciones metabólicas y electrolíticas.

1. Sueroterapia: $2.000-3.000 \mathrm{ml} / 24 \mathrm{~h}$, alternando suero fisiológico con glucosado $10 \%$, conseguir diuresis de $\geq 1.000 \mathrm{ml} / 24 \mathrm{~h}$.

2. Reposición de electrolitos:

- Sodio: 60-150 mEq de $\mathrm{ClNa} / 24 \mathrm{~h}$, evitar reposición rápida.

- Potasio: según los niveles en sangre:

$-\geq 2,5 \mathrm{mEq} / \mathrm{l}: 10 \mathrm{mEq} / \mathrm{h}$.

$-\leq 2 \mathrm{mEq} / \mathrm{l}$, trastornos en el ECG y/o alteraciones musculares: 40 $\mathrm{mEq} / \mathrm{h}$.

- Calcio: 0,2-0,3mEq/24h de gluconato cálcico al $10 \%$.

- Fósforo: si <1mg/dl administrar fosfato monosódico ev 2,5-5 mg/ $\mathrm{kg}$ en $500 \mathrm{ml}$ de SF.

3. Prevenir alteraciones neurológicas (encefalopatía de Wernicke) con administración de vitamina B6 100 $\mathrm{mg} / 24 \mathrm{~h}$ y vitamina B1 $100 \mathrm{mg} / 24 \mathrm{~h}$.

4. Requerimientos nutricionales: reiniciar la dieta oral tras $24-48$ h sin vómitos, mejoría analítica y cese de la pérdida de peso. Hidratos de carbono $150-220 \mathrm{~g} / \mathrm{kg} / 24 \mathrm{~h}$, lípidos $0,5-3 \mathrm{gr} /$ $\mathrm{kg} / 24 \mathrm{~h}$ y proteínas $0,8-2 \mathrm{~g} / \mathrm{kg} / 24 \mathrm{~h}$.

5. Fármacos antieméticos:

- Metoclopramida $10 \mathrm{mg}$ ev c/8h.

- Ondansetrón 4 mg ev c/12h.

- Clorpromacina (Largactil®) 2,5-10 mg ev c/6-8h.
Los riesgos maternos más importantes son complicaciones como síndrome de Mallory-Weiss (dislaceraciones en esófago por vómitos), síndrome de Mendelson (neumonía por aspiración), síndrome de Boherhave (rotura esofágica), encefalopatía de Wernicke-Korsakoff, hemorragia retiniana ${ }^{2}$.

Las hiperemesis gravídicas asociadas a pérdida de peso de $>5 \%$ se asocian a retraso de crecimiento fetal intrauterino.

\section{DIARREA AGUDA}

En la valoración en la consulta de urgencias de una gestante con diarrea se debe tener en cuenta ${ }^{4}$ :

1. Duración, frecuencia y características de las deposiciones:

- Diarrea aguda: duración $\leq 14$ días.

- Diarrea persistente: duración >14 días.

- Diarrea crónica: duración $>30$ días.

- Diarrea grave: $\geq 4$ deposiciones al día durante $>3$ días.

La presencia de sangre orienta hacia un posible origen bacteriano.

2. Anamnesis para identificar el patógeno y guiar en el tratamiento empírico, investigar factores como exposición ocupacional, viajes, mascotas, hobbies, fármacos, casos próximos. La comida consumida y el tiempo desde el consumo a la clínica ayuda en la identificación del germen:

- < 6h: Staphylococus aureus o Bacillus cereus; 8-16 h: Clostridium perfringens, $>16 \mathrm{~h}$ : infección viral $\mathrm{o}$ bacteriana.

3. Asociación de dolor, tenesmo, vómitos (síntoma principal de presentación en caso de intoxicación alimentaria por $S$. aureus, B. cereus $y$ Norwalk virus), fiebre (sugiere infección por bacterias invasivas como Salmonella, Shigella, Campylobacer, virus entéricos, u organismos citotóxicos como Clostridium difficile o Entamoeba histolytica) o signos peritoneales. 
4. Valoración de la deplección de volumen extracelular: hipotensión ortostática, disminución de la turgencia cutánea, taquicardia. Las pruebas complementarias incluyen hemograma, bioquímica con electrolitos y coprocultivo en caso de presentarse heces con sangre, deshidratación o diarrea grave.

El tratamiento en la mayoría de los casos permite una actitud expectante, por el carácter autolimitado y sólo requieren rehidratación y reposo intestinal. La pauta a seguir es:

- Dieta absoluta en las primeras 24 horas, con limonada alcalina según tolerancia, y posteriormente pasar a dieta astringente (pollo, zanahoria, manzana, arroz hervido, plátano) ${ }^{5}$. Si en $24 \mathrm{~h}$ no hay respuesta hacer revaloración, y si presenta vómitos administrar do-

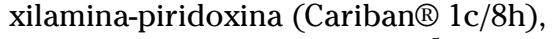
metoclopramida (10 mg c/8h) .

- En general no usar fármacos astringentes, si bien la caolina y pectina son los antidiarreicos de elección en el embarazo, porque no se absorben ${ }^{6}$.

- Considerar tratamiento antibiótico empírico a la espera del resultado de coprocultivo cursado previamente, en caso de presentar $>8$ deposiciones al día, deshidratación severa, síntomas de $>1$ semana, sospecha de diarrea bacteriana (fiebre $>38,5^{\circ} \mathrm{C}$, diarrea sanguinolenta). Se puede utilizar azitromicina $500 \mathrm{mg}$ c/24 horas durante 3 días, o eritromicina $500 \mathrm{mg} \mathrm{c} / 12 \mathrm{~h}$ durante 5 días.

- Se debe solicitar cultivo especial para parásitos en caso de diarrea persistente (>14 días) o diarrea sanguinolenta sin leucocitos en heces ${ }^{6}$ y pensar en Clostridium difficile cuando se presente tras toma de antibióticos. En estos casos se trata con metronidazol (amebiasis, giardiasis, $C$. difficile) $^{6}$.

- Se considerará el ingreso cuando precisen rehidratación ev, y endoscopia en casos de duda diagnóstica entre enfermedad inflamatoria intestinal y diarrea infecciosa (diarrea crónica o aguda que empeora progresivamente), inmunocomprometidas con riesgo de infecciones oportunistas como citomegalovirus ${ }^{6}$.

\section{DOLOR ABDOMINAL AGUDO EN EL EMBARAZO}

Las patologías que provocan dolor abdominal agudo en el embarazo pueden ser clasificadas en ginecológicas y no ginecológicas o médicas. Las patologías no ginecológicas pueden presentarse diferentes clínicamente o su proceso diagnóstico o tratamiento verse modificados por el embarazo $^{7}$. Además algunos síntomas abdominales pueden estar causados por cambios fisiológicos del embarazo (náuseas, vómitos, pirosis) y puede ser difícil diferenciarlos de procesos patológicos.

Dentro del proceso diagnóstico la exploración abdominal está distorsionada por el desplazamiento visceral que ocasiona el útero gestante, dificultando la palpación de masas, además aleja el peritoneo parietal del órgano inflamado enmascarando los signos de peritonitis. Las pruebas de laboratorio estudiadas en el dolor abdominal sufren cambios: leucocitosis moderada (hasta 16.000 leucocitos $/ \mathrm{mm}^{3}$ en $2^{\circ}$ y $3^{\circ}$ trimestre, y hasta 20.000-30.000 leucocitos $/ \mathrm{mm}^{3}$ en el parto-puerperio), anemia dilucional, aumento de fosfatasa alcalina, hiponatremia leve, aumento de VSG, hiperinsulinemia (hipoglucemia en ayuno e hiperglucemia postprandial). Algunas pruebas radiológicas pueden conllevar riesgos fetales (TAC, radiografías) ${ }^{7}$.

\section{Patología ginecológica ${ }^{8}$}

Puede presentarse:

1. Torsión o rotura de masa anexial: $1 / 1.800$ y $1 / 45.000$ embarazos respectivamente. La torsión es más frecuente en la gestante que en la no gestante ( 28 vs $7 \%$ ), generalmente en la semana 6 , a la 16 y en el lado derecho.

- Clínica: dolor e inicio súbito en fosa ilíaca, a veces intermitente, con náuseas, vómitos, fiebre y leucocitosis.

- Diagnóstico: clínica apoyado por ecografía (tamaño, contenido) con o sin Doppler que da información del flujo sanguíneo, disminuido o ausente en caso de torsión.

- Tratamiento: quirúrgico si se sospecha torsión, extirpando el anejo 
si hay signos de necrosis, o quistectomía si recupera el color tras destorsionar. En caso de rotura el tratamiento es conservador, reservando la cirugía para los casos que se acompañen de inestabilidad hemodinámica o dolor intenso que no cede a analgésicos ev. Si se produce la rotura de un cuerpo lúteo gestacional $<8$ s se debe suplementar con progesterona.

2. Miomas uterinos: el $10 \%$ de las mujeres con miomas presentan dolor en el embarazo por degeneración roja (infarto hemorrágico o trombosis) o por torsión en caso de miomas pediculados. En estos casos presentan aumento de transaminasas, CK y LDH.

- Clínica: dolor agudo, hipersensibilidad uterina, náuseas, vómitos, leucocitosis, febrícula.

- Diagnóstico: clínica y ecografía.

- Tratamiento médico con reposo, analgésicos vo o ev. Cirugía en casos de miomas pediculados complicados, contraindicada en miomas intramurales por el riesgo de sangrado.

\section{Patología no ginecológica}

\section{Apendicitis aguda ${ }^{7}$}

Se produce en 1/1.500-2.000 embarazos. Es más frecuente en el $2^{\circ}$ trimestre.

Se manifiesta con dolor en cuadrante inferior derecho (CID) del abdomen, hasta $1 / 3$ presentan hematuria y piuria (por proximidad con el uréter).

Ante la sospecha clínica se puede realizar ecografía con compresión gradual (gold standard), que es diagnóstica de apendicitis cuando se visualiza una estructura tubular en el CID con diámetro máximo $>6 \mathrm{~mm}$. La RMN puede ser útil si el diagnóstico es incierto.

La decisión de operar debe basarse en hallazgos clínicos, de imagen y juicio clínico. La incisión se realiza en el punto de McBurney o con más frecuencia en el punto de máxima tensión. Se puede realizar laparoscopia pero hay datos limitados sobre su seguridad y eficacia.
En el embarazo existe el riesgo de que un apéndice infectado se rompa, especialmente en el $3^{\text {er }}$ trimestre, probablemente por retraso en el diagnóstico y tratamiento. Se produce perforación a las $24 \mathrm{~h}$ del inicio del cuadro $25 \%$, a las 36 h $50 \%$ y a las $48 \mathrm{~h}$ del $75 \%$; en general se perforan el $43 \%$ respecto al $4-9 \%$ de la población general. Por ello se admite una tasa mayor de cirugía en blanco que en la no embarazada (25-30\%).

El riesgo de pérdida fetal está aumentado en caso de perforación ( $36 \%$ vs $1,5 \%$ ) o cuando hay peritonitis o absceso peritoneal.

La apendicectomía en el $1^{\circ}$ trimestre aumenta el riesgo de aborto (33\%) frente al riesgo de parto prematuro cuando se realiza en el $2^{\circ}$ trimestre ( $14 \%$ ), y pocas o ninguna complicación en el $3^{\text {er }}$ trimestre (no hay riesgo de dehiscencia en caso de parto vaginal si se aproxima la fascia correctamente).

\section{Colecistitis aguda ${ }^{8}$}

Es la segunda causa de abdomen agudo en la embarazada, en 1: 6.000-10.000 embarazos.

La clínica se presenta de forma similar a la no gestante, con dolor en hipocondrio derecho irradiado a hombro o espalda, signo de Murphy menos frecuente, pirosis, nauseas, vómitos (50\%), fiebre, taquicardia e ictericia (5\%).

Se diagnostica mediante ecografía, con exactitud en $>95 \%$; en la analítica sugiere el diagnóstico el aumento de transaminasas y bilirrubinas.

Para su tratamiento inicialmente se administran analgésicos, antiespasmódicos, hidratación ev, ayuno, antibióticos, sonda nasogástrica si presenta vómitos. Es suficiente en el $62-84 \%$.

Es necesario valorar colecistectomía si el cuadro persiste o presenta ictericia, de preferencia programada en segundo trimestre por laparoscopia (presiones de 10-12 mmHg).

Las complicaciones más frecuentes son: abscesos, empiema, colangitis ascendente, perforación, pancreatitis. 


\section{Pancreatitis aguda ${ }^{8}$}

Acontece en 1:3.300 embarazos; más frecuente en el tercer trimestre y postparto. Causada generalmente por colecistolitiasis (70\%), hipertrigliceridemia, fármacos (diuréticos, antibióticos, antihipertensivos...), alcoholismo, infecciones...

La clínica aparece con dolor epigástrico irradiado a espalda, con náuseas y vómitos, taquicardia, fiebre.

Se diagnostica por un aumento de amilasa sérica (límite normal en el embarazo 100 $\mathrm{UI} / 100 \mathrm{ml}$, aumento de lipasa sérica (normal $200 \mathrm{U} / 100 \mathrm{ml}$ ) e hipocalcemia. La ecografía es útil para detectar complicaciones como hemorragia, abscesos, así como para descartar la colecistolitiasis como causa.

Las complicaciones que pueden darse son: hipocalcemia, síndrome de distrés respiratorio del adulto, abscesos, liponecrosis. Mortalidad materna del $37 \%$ y fetal de $37,9 \%$. Para clasificar la gravedad y el pronóstico se utilizan los criterios de Ranson, al ingreso: edad $>55$ años, leucocitos $>16.000$, glucosa $>200 \mathrm{mg} / \mathrm{dl}, \mathrm{LDH}>3590 \mathrm{U} / \mathrm{l}$, TGO > $250 \mathrm{U} / \mathrm{l}$; y a las 48 horas: caída del hematocrito $>10 \%$, nitrógeno de la urea plasmática $>5 \mathrm{mg} / \mathrm{dl}$, calcio sérico $<8 \mathrm{mg} /$ dl, presión $\mathrm{O} 2$ arterial $<60 \mathrm{~mm} \mathrm{Hg}$, déficit de bases $>4 \mathrm{mMol} / \mathrm{l}$, y secuestro de líquidos $>6$ litros. Con $<3$ criterios el riesgo de mortalidad es bajo.

Se deben administrar líquidos ev, ayuno, sonda nasogástrica, antibióticos, nutrición parenteral total. Se reserva la cirugía para las complicaciones como abscesos, pseudoquistes y necrosis hemorrágica.

\section{Obstrucción intestinal}

Tiene lugar en 1/2.500-3.000 embarazos. Más frecuente en el $3^{\text {er }}$ trimestre. Suponen factores de riesgo antecedente de cirugía abdominal e historia de estreñimiento.

Tríada de dolor, vómito y estreñimiento constituye la sintomatología típica; según el nivel de obstrucción presenta frecuencia del dolor en ataques cada 4-5 minutos en caso de obstrucción alta o cada 15-20 minutos cuando la obstrucción es baja. Asocia distensión abdominal, timpanismo, fiebre, leucocitosis y alteraciones hidroelectrolíticas.
El diagnóstico se hace mediante una radiografía de abdomen donde aparecen niveles hidroaéreos y dilatación de asas.

El tratamiento adecuado es hidratación ev y administración de electrolito, descompresión con sonda nasogástrica, y cirugía si no resulta suficiente lo anterior. El retraso en el diagnóstico aumenta el riesgo de muerte materna y fetal a 6 y $26 \%$ respectivamente. Tras cirugía llega a término sólo un $33-38 \%$.

\section{Síndrome de Ogilvie o pseudoobstrucción colónica}

Es un íleo paralítico y ocurre en el postparto en el $10 \%$. Se manifiesta por distensión abdominal severa, fiebre, leucocitosis, náuseas y vómitos.

El tratamiento a efectuar es colonoscopia o neostigmina (contraindicada en el embarazo). Conlleva una mortalidad del $10 \%$ sin perforación que puede llegar al $70 \%$ con perforación.

\section{HEPATOPATÍAS EN LA GESTANTE EN LA CONSULTA DE URGENCIAS}

Las hepatopatías no son frecuentes durante la gestación, con una incidencia actual de 1/500-5.000 embarazos, pero cuando aparecen revisten gravedad. El 75\% corresponden con hepatitis viral o colestasis intrahepática del embarazo. El diagnóstico es fundamentalmente clínico, apoyado por datos de laboratorio. El tratamiento a menudo requiere ingreso hospitalario.

La clasificación de las hepatopatías en el embarazo según su relación etiológica es la siguiente ${ }^{9}$ :

1. Enfermedad hepática inducida por el embarazo:

- Hígado graso agudo del embarazo.

- Colestasis intrahepática del embarazo.

- Hiperemesis gravídica.

- Preeclampsia o síndrome HELLP.

2. Enfermedad hepática crónica preexistente:

- Hepatitis viral crónica.

- Hepatopatía alcohólica.

- Cirrosis. 
- Neoplasias benignas o malignas.

- Miscelánea: porfirias, enfermedad de Wilson, hidatidosis...

3. Enfermedad hepática nueva desarrollada durante el embarazo.

- Hepatitis viral aguda.

- Síndrome de Budd Chiari (trombosis venosa en venas hepáticas).

- Hepatitis tóxica.

- Metástasis hepática.

- Colestasis asociada a sepsis, particularmente de origen urinario.

El embarazo se asocia con muchos cambios fisiológicos que deben ser considerados en el proceso diagnóstico de la patología hepatobiliar ${ }^{10}$.

1. Examen físico: síntomas clásicos asociados a enfermedad hepática crónica como arañas vasculares y eritema palmar son frecuentes durante el embarazo. La palpación resulta difícil, si se palpa se presupone anormal.
2. Ecografía: el tracto biliar no sufre cambios, no obstante hay producción de bilis litogénica con espesamiento biliar.

3. Hemodinámica: el volumen plasmático aumenta un $50 \%$ de las 6 a las 36 semanas, con aumento de los glóbulos rojos no proporcional (20\%), con hemodilución. El gasto cardiaco aumenta hasta el $2^{\circ}$ trimestre y luego se estabiliza hasta el parto, con disminución del porcentaje que se destina al hígado, pero manteniendo el flujo sanguíneo a ese órgano sin cambios.

4. Disminuyen los niveles de albúmina $\mathrm{y}$ aumentan los de colesterol (hasta $60 \%)$ y triglicéridos.

5. Aumenta la fosfatasa alcalina (x 2-4) en el $3^{\text {er }}$ trimestre (origen placentario), la bilirrubina total y libre disminuye, y el fibrinógeno aumenta tardíamente.

Tabla 1. Hepatopatías iniciadas en la gestación.

\begin{tabular}{|c|c|c|c|c|c|}
\hline & Colestasis & $\begin{array}{c}\text { Preeclampsia } \\
\text { eclampsia }\end{array}$ & $\begin{array}{c}\text { Hígado graso } \\
\text { agudo }\end{array}$ & Hepatitis viral & Hígado normal \\
\hline $\begin{array}{l}\text { Trimestre de } \\
\text { inicio }\end{array}$ & $3^{\text {er }}$ & $3^{\text {er }}$ & $3^{\text {er }}$ & $1^{\mathrm{o}}, 2^{\mathrm{o}}, 3^{\mathrm{er}}$ & \\
\hline Clínica & Prurito & $\begin{array}{l}\text { - HTA } \\
\text { - Edemas } \\
\text { - Albuminuria }\end{array}$ & $\begin{array}{l}\text { - Náuseas y } \\
\text { vómitos } \\
\text { - Dolor } \\
\text { abdominal } \\
\text { - Confusión }\end{array}$ & $\begin{array}{l}\text { - Náuseas y } \\
\text { vómitos } \\
\text { - Dolor } \\
\text { abdominal } \\
\text { - Prurito }\end{array}$ & $\begin{array}{l}\text { - Arañas } \\
\text { vasculares } \\
\text { - Eritema palmar }\end{array}$ \\
\hline Transaminasas & x 5 ó más & x 5 ó más & x 10 ó más & x 100 ó más & Normal \\
\hline Fosfatasa & x 7-10 ó más & x 2-3 ó más & x 3 ó más & x 2-3 ó más & x 2 ó más \\
\hline $\begin{array}{l}\text { Bilirrubina } \\
(\mathrm{mg} / \mathrm{dl})\end{array}$ & $<5$ & $\begin{array}{l}10 \text { (no } \\
\text { conjugada) }\end{array}$ & 10 & $<10$ & 1 \\
\hline $\begin{array}{l}\text { Tiempo } \\
\text { protrombina }\end{array}$ & $\mathrm{x} 2$ & $+/-$ & x 2 ó más & normal & \\
\hline Otros & $\begin{array}{c}\text { Ácidos biliares } \\
>12\end{array}$ & $\begin{array}{l}\text { Leucocitos } \\
20-30.000\end{array}$ & & $\begin{array}{l}\text { Leucocitos } \\
10-15.000\end{array}$ & \\
\hline
\end{tabular}

\section{Clínica}

Las manifestaciones clínicas ${ }^{10}$ incluyen ictericia, prurito, dolor abdominal, náuseas, vómitos, alteraciones en las pruebas de función hepática; la mayoría no son específicas del embarazo.

\section{Diagnóstico}

Como en el paciente no gestante, un abordaje práctico para la evaluación ante la sospecha de enfermedad hepatobiliar incluye una búsqueda sistemática de patrones que son característicos de una en- 
fermedad en particular y un juicioso proceso diagnóstico para excluir otras causas ${ }^{10}$. Así:

- Hiperemesis debe ser considerada en el diagnóstico de alteraciones de las enzimas hepáticas en el primer trimestre.

- Colestasis intrahepática del embarazo es preciso tenerla en cuenta en pacientes con prurito y test hepáticos anormales, especialmente al final del embarazo. Aumenta el riesgo de prematuriada de muerte fetal. Tratamiento con ácido ursodesoxicólico y parto.

- Hígado graso agudo del embarazo, preeclampsia y HELLP suele ocurrir tardíamente en el embarazo, generalmente en $3^{\text {er }}$ trimestre. El parto es el tratamiento primario.

- Hepatitis por drogas o virus se puede presentar en cualquier trimestre.

Es importante investigar los antecedentes médicos, incluyendo embarazos previos, y el uso de drogas vía parenteral o trasfusiones sanguíneas previas.

- Examen físico: temperatura, TA, proteinuria.

- Laboratorio: hemograma, transaminasas, tiempo de protrombina, creatinina, electrolitos, glucosa, ácido úrico. Serología de VHA, VHB,VHC y CMV. Valorar VHE si es país endémico. Niveles de ácidos biliares si hay sospecha. Sedimento y urocultivo.

- Ecografia de hígado y vías biliares.

En este capítulo se exponen las hepatopatías inducidas por la gestación y las de inicio en la gestación (Tabla 1).

\section{Colestasis intrahepática del embarazo ${ }^{9}$}

Síndrome caracterizado por presencia de prurito, ictericia o ambos, sin otra disfunción hepática importante. Suele presentarse en el $3^{\text {er }}$ trimestre o segunda mitad del embarazo, suele recurrir en sucesivos embarazos, más frecuente en los meses fríos.

\section{Clínica}

- Prurito generalizado, inicialmente palmo-plantar, más intenso por la noche, sin lesión dermatológica primaria (desaparece 1 o 2 semanas postparto).

- Ictericia: segunda causa de ictericia en el embarazo, afebril.

- Orina colúricas.

- Estado general poco afectado.

- Obstétrico: partos prematuros (25\%), meconio (49\%), signos de hipoxia intraparto (20\%).

\section{Diagnóstico diferencial}

- Prurito: parásitos, alérgicas, hongos.

- Ictericia: hepatitis viral, ictericia obstructiva.

\section{Tratamiento}

El tratamiento definitivo es el parto, si bien no se recomienda la finalización pretérmino de entrada sin otras complicaciones. Acido ursodesoxicólico $300 \mathrm{mg}$ c/8horas (dosis máxima $1.200 \mathrm{mg} /$ día), puede disminuir el prurito.

\section{Hígado graso agudo del embarazo ${ }^{9}$}

Muy poco frecuente, pero muy grave. Se suele presentar en el $3^{\text {er }}$ trimestre, más frecuente en gestaciones gemelares y asociado a preeclampsia.

\section{Clínica}

- Comienzo brusco y de evolución rápidamente progresiva.

- Dolor abdominal epigástrico.

- Vómitos incoercibles.

- Ictericia progresiva que aparece al cabo de unos días.

- Cefalea intensa, hemorragias cutáneomucosas, astenia.

- Cambios en el nivel de conciencia, puede llegar al coma.

- Diátesis hemorrágica por CID.

- Shock y muerte materna.

- Muerte fetal.

\section{Laboratorio}

Aumento de bilirrubina, tiempo de protrombina y tiempo parcial de tromboplasti- 
na, ácido úrico, hiperamoniemia, hipoglucemia, aumento moderado de transaminasas, signos de CID (trombopenia, hipofibrinogenemia, aumento de PDF.

A veces puede ser difícil diferenciar este cuadro de una preeclampsia severa, ya que el dolor abdominal puede estar presente en los dos, y hasta el 50\% de las mujeres con hígado agudo graso pueden presentar hipertensión y proteinuria. La aparición de hipoglucemia es un hecho usual, como consecuencia de una disminución de la glucogenolisis hepática, puede servir para diferenciar esta entidad de la preeclampsia severa.

\section{Tratamiento}

- Tratamiento de sostén en UCI.

- Tratamiento de CID si está presente.

- Finalización precoz del embarazo: inducción si están estables madre y feto, si no cesárea.

\section{Pronóstico}

Mortalidad materna del $75-85 \%$, supervivencia de $12 \%$ de los recién nacidos.

\section{Hepatitis viral aguda ${ }^{11}$}

Es la causa más frecuente de ictericia en el embarazo, pero muchos cuadros evolucionan de forma subictérica, por lo que se ha subestimado su incidencia en la gestación.

Suele iniciarse con fatiga, malestar, anorexia, náuseas y vómitos. En la fase inicial puede aparecer sintomatología gripal (tos, cefalea, mialgias). Esta sintomatología suele desaparecer con la aparición de la ictericia. El 70-80\% evoluciona de forma benigna. No existe riesgo de malformaciones congénitas. Aumenta el riesgo de parto prematuro. Existe vacunación para VHB y VHA. Tratamiento similar a las pacientes no gestantes: reposo y dieta.

\section{Hepatitis B}

No aumenta el riesgo de prematuridad o mortalidad materno-fetal. Riesgo de trasmisión perinatal, especialmente en caso de infección en el $3^{\text {er }}$ trimestre o $\mathrm{HBeAg}+(90 \%$ de trasmisión) o $\mathrm{HBsAg}+(10 \%$ de trasmisión). Puede administrarse vacunación y gammaglobulina en el embarazo, y no asocian teratogenicidad.

\section{APARATO CARDIOVASCULAR}

\section{Varices}

Las varices son venas superficiales dilatadas y tortuosas con válvulas incompetentes ${ }^{12}$, que aparecen en partes declives del cuerpo. La clínica que producen incluye pesadez, prurito, dolor sordo, hinchazón o edemas. El diagnóstico es clínico, y no están indicadas exploraciones complementarias, salvo que existan complicaciones.

Las complicaciones más frecuentes por las que una gestante con varices conocidas o no puede acudir a urgencias son ${ }^{13}$ :

1. Varicoflebitis o trombosis venosa superficial: evolución generalmente benigna. Se manifiestan por dolor, edema, aumento de temperatura, enrojecimiento, tumefacción y aparición de un cordón palpable doloroso. El tratamiento incluye reposo con elevación de la extremidad, medias elásticas de compresión, analgésicos, antiinflamatorios no esteroideos, y deambulación precoz, siendo controvertido el uso de heparinas de bajo peso molecular por la posibilidad de embolización.

2. Varicorragias: complicación muy rara, que responde a elevación del miembro por encima del corazón y presión local durante 15 minutos.

3. Enfermedad tromboembólica venosa que incluye trombosis venosa (TVP) profunda y tromboembolismo pulmonar (TEP)

\section{Trombosis venosa profunda}

El embarazo supone un factor de riesgo para la enfermedad tromboembólica venosa (1/1.000-2.000 embarazos) $)^{12}$.

Cerca del 90\% de las TVP se presentan en la pierna izquierda (probablemente por el aumento de la presión de la arteria ilíaca común izquierda sobre la vena ilíaca de 
ese lado, $\mathrm{y}>40 \%$ son la porción iliofemoral (más grave y más riesgo de TEP) ${ }^{12}$.

\section{Clínica}

Puede presentarse de forma asintomática o bien presentarse inicialmente con su complicación más grave, el TEP ${ }^{12}$. La clínica más habitual es dolor en la extremidad con sensación de tensión, edema desde la raíz del muslo, dolor a ala palpación del trayecto venoso y cambios en la coloración ${ }^{12}$. El signo de Homans se presenta en el $30 \%$ y se refiere al dolor referido a la pantorrilla con la dorsiflexión del pie ${ }^{14}$.

\section{Diagnóstico}

El estándar de diagnóstico es la prueba de compresibilidad con ecografía o ecoDoppler $^{12}$. Si la sospecha clínica es alta y el resultado es negativo se debe realizar de forma seriada el $3^{\text {er }}$ y $7^{\circ}$ día. No permite diagnosticar las localizadas a nivel de ilíaca, en cuyo caso pueden ser útiles RMN o TAC (ésta con limitaciones por el riesgo de la radiación ionizante); o las localizadas a nivel de la pantorrilla pudiendo realizarse la venografía a ese nivel. La pletismografía de impedancia que mide cambios de volumen de la extremidad por inflado y desinflado de un manguito en el muslo puede ser útil en casos de trombos oclusivos proximales $^{14}$.

Así como fuera del embarazo el dímero D resulta útil para excluir el diagnóstico en caso de estar en niveles bajos, en el embarazo no resulta útil porque presenta un aumento fisiológico.

\section{Tratamiento $^{14}$}

Debe iniciarse rápidamente tras el diagnóstico radiológico o ante alta sospecha clínica hasta la realización de un diagnóstico objetivo, salvo contraindicación rigurosa. El objetivo principal es prevenir el TEP y la extensión del trombo.

Terapia anticoagulante: de elección Heparina de Bajo Peso Molecular (HBPM), con dosis inicial en función del peso al inicio del embarazo. Debemos mantenerlo todo el embarazo y al menos las seis sema- nas del puerperio (en total un mínimo de 3 meses).

En el parto suspender la administración de HBPM 24 h antes; si TTPa es $>2$ veces lo normal o se produce hemorragia administrar sulfato de protamina $(1 \mathrm{mg}$ neutraliza 100UI de heparina de forma inmediata, no pasar más de $50 \mathrm{mg}$ en 10 minutos).En el puerperio, tras el $2^{\mathrm{o}}$ ó $3^{\text {er }}$ día la heparina se puede sustituir por anticoagulantes orales.

- Enoxaparina (Clexane®) (HBPM):1 $\mathrm{mg} / \mathrm{Kg} / 12 \mathrm{~h}$.

- Dalteparina （Fragmin $®)(H B P M): 100$ $\mathrm{U} / \mathrm{Kg} / 12 \mathrm{~h}$.

- Tinzaparina (HBPM): $175 \mathrm{U} / \mathrm{Kg}$.

- HNF: 5000 UI iniciales y continuar con perfusión de 1000-2000 UI/h. Control de TTPa (objetivo es 1,5-2 veces su valor normal) o de anti-factor $\mathrm{Xa}$ a las $6 \mathrm{~h}$ y luego al menos 1 vez al día si se emplea esta heparina.

Además se dede recomendar reposo en cama, con elevación de la extremidad y ejercicios de flexión y extensión del pie, con inicio de la deambulación cuando el dolor lo permita, vendas elásticas en la extremidad afecta y aplicación de calor húmedo.

\section{Cardiopatías y embarazo en la consulta de urgencias}

El embarazo implica unos cambios a nivel cardiovascular fisiológicos que se reflejan en unos síntomas que no deben ser considerados como signos de alarma: disminución de la tolerancia al esfuerzo, disnea y fatigabilidad, edemas de miembros inferiores, palpitaciones y mareos y cuadros sincopales ${ }^{15}$. También hay cambios en las pruebas complementarias a tener en cuenta $^{16}$ :

1. ECG: horizontalización y desviación del eje a la izquierda (por la elevación del diafragma), acortamiento de PR y QT con aumento de la frecuencia cardiaca, anomalías inespecíficas de ST y T en el 4-14\%.

2. Alteración de la repolarización, extrasístoles supraventriculares o ventriculares.

3. Rx tórax: aumento del índice cardiotorácico y del cono pulmonar. 
4. Ecocardiografía: pequeño derrame pericárdico, aumento de las cámaras y del díámetro del anillo valvular.

5. Test de esfuerzo: protocolos de bajo nivel y monitorización fetal.

\section{Fallo cardiaco ${ }^{15}$}

El embarazo se asocia con sustanciales cambios hemodinámicos, incluyendo aumento del 30 a $50 \%$ del gasto cardiaco y del volumen sanguíneo. En mujeres con antecedentes de fallo cardiaco u otras patologías cardiovasculares estos cambios pueden llevar a descompensación clínica. Además, mujeres sin historia de enfermedad cardiovascular pueden desarrollar fallo cardiaco por enfermedades adquiridas en el embarazo, como la miocardiopatía periparto. El cuadro de fallo cardiaco puede presentarse en dos circunstancias:

1. Mujeres con antecedente de patología cardiaca conocida con riesgo de descompensación en el embarazo: miocardiopatía, estenosis mitral severa, estenosis aórtica severa, insuficiencia mitral o aórtica severa, y amplios defectos de septo auricular, Síndrome de Eisenmenguer, síndrome de Marfan, infarto, cardiopatías congénitas (coartación de aorta), o portadoras de prótesis mecánicas.

2. Mujeres que se presentan con fallo cardiaco en el embarazo o periparto de novo.

\section{Clínica}

Las gestantes con fallo cardiaco descompensado frecuentemente se presenta con disnea progresiva o tos persistente, que puede o no asociarse con molestias torácicas.

\section{Diagnóstico}

Se hace con el cuadro clínico de síntomas y signos y con los hallazgos de laboratorio. La evaluación inicial incluye:

1. Historia detallada y examen físico, con énfasis en la presencia de enfermedad cardiovascular previa.
2. Ecocardiografía, que puede revelar malformación estructural no detectada o empeoramiento de la función del ventrículo izquierdo.

3. ECG, que puede revelar hipertrofia ventricular izquierda, anomalías de la aurícula izquierda, isquemia miocárdica o fibrilación auricular.

4. Hemograma, electrolitos, función renal; añadir según clínica gasometría o enzimas cardiacas.

5. Radiografía de tórax, pero se puede obviar si el diagnóstico de edema pulmonar es clínicamente evidente.

6. Valorar colocación de catéter SwanzGanz.

\section{Diagnóstico diferencial}

Daño pulmonar agudo por infección y/o tocolisis, embolismo de líquido amniótico, tromboembolismo pulmonar, neumonía, infarto agudo de miocardio preeclampsia severa.

\section{Tratamiento}

El objetivo es similar al del paciente no gestante:

1. Estabilización hemodinámica.

2. Aliviar los síntomas.

3. Cuando es posible, continuar con tratamiento crónico propio de las enfermedades cardiovasculares crónicas.

Los métodos para conseguirlo incluyen:

1. Diuréticos para disminuir el edema pulmonar. Preferibles los de asa (por ejemplo furosemida), añadir tiacidas si no es suficiente (vigilar el riesgo de diátesis hemorrágica e hiponatremia fetal).

2. Disminución de la postcarga y control de la HTA, hidralacina de elección; si no se tolera, amlodipino.

- En caso de descompensación cardiaca con HTA se puede usar nitroglicerina ev. Si es preciso disminuir la postcarga de forma marcada se puede utilizar nitroprusiato, como en caso de urgencia hipertensi- 
va o insuficiencia mitral o aórtica agudas, pero con limitaciones de dosis y duración en el $3^{\text {er }}$ trimestre por riesgo de intoxicación fetal por cianida.

- En caso de descompensación cardiaca con hipertensión o con edema pulmonar a pesar de oxígeno, diuresis y vasodilatadores. La dobutamina tiene propiedades inotrópicas y vasodilatadoras, la dopamina tiene efectos variables en la vascularización periférica.

3. Anticoagulación: no hay datos sobre el riesgo de tromboembolismo por disfunción del ventrículo izquierdo (fracción de eyección $\leq 30 \%$ ) pero es aconsejable la profilaxis antitrombótica.

4. Evitar IECAS Y ARA II, riesgo de fallo renal, malformaciones cardiovasculares o del SNC fetal o incluso muerte neonatal. Idealmente supenderlos antes del embarazo. Evitar antagonistas de la aldosterona.

Una de las causas de fallo cardiaco en el embarazo es la miocardiopatía periparto que describimos a continuación.

\section{Miocardiopatía periparto ${ }^{17}$}

Incidencia 1/1.300-15.000 embarazos en EEUU, mayor en embarazo gemelar, multíparas, >30 años y raza negra, así como las que la han padecido con anterioridad (alto riesgo de mortalidad). Etiología desconocida.

\section{Clínica}

Pueden aparecer en los 3 últimos meses del embarazo o en los 6 tras el parto, y son síntomas de insuficiencia cardiaca congestiva, dolor precordial, palpitaciones y a veces embolia periférica o pulmonar.

\section{Diagnóstico}

De exclusión con otras causas de dilatación y disfunción de ventrículo izquierdo.

\section{Tratamiento}

El de la insuficiencia cardiaca aguda con oxígeno, diuréticos, digital y vasodila- tadores como hidralacina, asociar anticoagulación. Si no responde se puede intentar inmunosupresión o azatioprina, o incluso trasplante cardiaco.

Suele haber recuperación de tamaño y funcional en el $50 \%$, en el otro $50 \%$ el deterioro conduce a la muerte o a la disfunción ventricular izquierda mantenida.

\section{Arritmias $^{16}$}

Las anomalías de la conducción y las arritmias pueden aparecer de novo o pueden exacerbarse en el embarazo probablemente en relación con el estado hiperdinámico y las alteraciones hormonales y del sistema autonómico. La presencia de cardiopatía congénita supone un factor de riesgo para desarrollar arritmias supraventriculares o ventriculares, incluso tras su reparación.

\section{Taquicardia supraventricular}

Requiere estudio para descartar cuadros como pérdida sanguínea, infección, fallo cardiaco, tirotoxicosis o TEP, porque si se excluyen rara vez precisan tratamiento. Rara vez aparecen por primera vez en el embarazo, pero se hacen más frecuentes si hubo episodios previos. Generalmente benignas, sólo requieren tratamiento las sintomáticas con maniobras vagales, y si fracasan se puede utilizar adenosina con seguridad.

\section{Taquicardia ventricular}

Muy rara sin cardiopatía de base (tetralogía de Fallot corregida, prolapso mitral). Suelen responder bien a tratamiento médico. Puede ser la manifestación inicial de la miocardiopatía periparto.

\section{Alteraciones de conducción}

- Bloqueo primer grado. Raro sin cardiopatía congénita o reumática de base. No implica riesgos fetales o maternos.

- Bloqueo de segundo grado. Asociada a cardiopatía de base como tetralogía de Fallot o CIV corregidas o a tratamiento con digoxina. Si no presentan bradicardia no requieren tratamiento. 
- Bloqueo completo. Puede ser adquirido, tras corrección de cardiopatía congénita, o congénito. Sin riesgos fetales ni maternos si no asocia bradicardia sintomática.

Los antiarrítmicos más utilizados en el embarazo son la quinidina y procainamida, pero se debe controlar la dosis por el riesgo de toxicidad, parto prematuro, aborto espontáneo y lesión del VIII par craneal fetal. No existen suficientes estudios con flecainamida ni propafenona. La amiodarona produce hipotiroidismo fetal y pequeños para la edad gestacional.

\section{Parto de la gestante cardiópata}

La clasificación de los fármacos en uso en la gestante cardiópata según la $\mathrm{FDA}^{17}$ se exponen en la Tabla 2.

Idealmente toda cardiópata embarazada debe ser valorada previo al parto por el equipo obstétrico, anestesista y cardiólogo ${ }^{18}$.
La cardiópata debería tener un parto vaginal, porque implica menos riesgo cardiaco que una cesárea. Además debería ser un parto de inicio espontáneo, pero a veces por alteraciones de la adecuación del corazón y la circulación en el embarazo el parto debe ser inducido bajo condiciones controladas. El momento de la inducción debe ser individualizado, teniendo en cuenta el estado cardiaco, las condiciones del cérvix y la maduración pulmonar fetal (evitar un parto inducido largo con cérvix desfavorable), además deberá planearse en la medida de lo posible el parto durante la jornada laboral cuando los servicios hospitalarios están a pleno rendimiento ${ }^{19}$.

A menudo, si el cérvix es favorable sólo es preciso el uso de oxitocina, pero puede utilizarse prostaglandina $\mathrm{E}$ para maduración cervical (puede disminuir la resistencia vascular sistémica, disminuir la TA e incrementar la frecuencia cardiaca, sobretodo E2 más que E1).

Tabla 2. Clasificación de los fármacos de uso en cardiopatía según FDA.

\begin{tabular}{|l|l|c|}
\hline \multicolumn{1}{|c|}{ Fármacos } & Nombre & Categoría \\
\hline Seguros & Betabloqueantes & $\mathrm{C}$ \\
& Metildopa & $\mathrm{B}$ \\
& Hidralacina & $\mathrm{C}$ \\
& Digoxina & $\mathrm{C}$ \\
& Adenosina & $\mathrm{C}$ \\
& Quinidina & $\mathrm{C}$ \\
\hline Precaución & Diuréticos & $\mathrm{C}$ \\
& Heparina & $\mathrm{C}$ \\
\hline No puede establecerse & Nitroprusiato sódico & $\mathrm{C}$ \\
seguridad & Calcioantagonistas & $\mathrm{C}$ \\
& Procainamida & $\mathrm{B}$ \\
& HeparinaBPM & $\mathrm{C}$ \\
\hline Inseguros o teratogénicos & Nitratos & $\mathrm{C}$ 1 $^{\circ} \mathrm{T}, \mathrm{D} 2^{\circ} \mathrm{T}$ \\
& IECAS & $\mathrm{D}$ \\
& Warfarina & $\mathrm{C}$ \\
& Amiodarona & \\
\hline
\end{tabular}

Deberían realizarse todos los procesos que se detallan:

1. Profilaxis de endocarditis bacteriana ${ }^{18}$

Las indicaciones de profilaxis de endocarditis son las mismas que para la po- blación no embarazada. La bacteriemia se produce sólo en el 0,5-3\% de los partos normales y no hay evidencia de que la profilaxis antibiótica sea necesaria o efectiva en estos casos, pero sí en los partos complicados prolongados o quirúrgicos; pero como 
en general no se conoce cómo se va a desarrollar el parto se recomienda en todas las gestantes con alto y moderado riesgo de endocarditis infecciosa (Tabla 3).

Tabla 3. Recomendaciones de la Asociación Americana del Corazón.

\begin{tabular}{ll}
\hline Alto riesgo & Válvulas protésicas \\
& Endocarditis previa \\
& Cardiopatía congénita cianótica (tetralogía de Fallot, TGA) \\
& Shunts pulmonares quirúrgicos \\
\hline \multirow{2}{*}{ Riesgo moderado } & Resto de cardiopatías congénitas \\
& Enfermedad valvular adquirida (enf. reumática) \\
& Miocardiopatía hipertrófica \\
& Prolapso mitral con insuficiencia mitral \\
\hline Riesgo bajo & CIA tipo ostium secundum \\
& CIA, CIV, DA intervenidos \\
& Prolapso mitral sin insuficiencia \\
\hline
\end{tabular}

La pauta antibiótica es ampicilina $2 \mathrm{~g}$ y gentamicina $1,5 \mathrm{mg} / \mathrm{kg}$ ev 1 hora antes del parto y amoxicilina vo $500 \mathrm{mg} 6$ horas después. En alérgicas vancomicina $1 \mathrm{~g}$ ev en 1-2 horas y gentamicina $1,5 \mathrm{mg} / \mathrm{kg}$ ev; completar el tratamiento 30 minutos antes del procedimiento.

2. Analgesia/anestesia ${ }^{19}$

- Opiáceos ev o im.

- Anestesia epidural es la recomendada porque reduce el aumento de la actividad simpática asociada al dolor, reduce la necesidad de pujo precoz, y presta anestesia excelente para tocurgia. Utilizar con precaución en la cardiópata cuyo gasto cardiaco puede disminuir como consecuencia de disminución de la precarga, ya que este tipo de anestesia reduce el retorno venoso (control riguroso de la hidratación ev para evitar sobrecarga).

3. Monitorización hemodinámica ${ }^{18}$

- TA, FC.

- Pulsioximetría y ECG según la condición de la gestante.

- Catéter Swan-Ganz habitualmente no necesario.

\section{Parto}

Cesárea reservada para indicaciones obstétricas, así como en el caso de disección aórtica, síndrome de Marfan con raíz aórtica dilatada y fallo al cambiar de warfarina a heparina al menos dos semanas antes del parto ${ }^{18}$; las condiciones para su realización son ${ }^{19}$ :

Aplicar anestesia general ya que asocia la inestabilidad hemodinámica asociada a la intubación y al agente anestésico, ya que:

- Asocia pérdida de sangre mayor que el parto vaginal (x 2 o más), sumado al riesgo por anticoagulantes.

- Existe riesgo aumentado de infección de la herida y endometritis.

- Existe riesgo de tromboflebitis posterior.

- Se debería realizar en posición en decúbito lateral o con inclinación y asistencia con fórceps o ventosa para descenso de la presentación al periné, no realizar pujos maternos para evitar los efectos circulatorios de la maniobara de Valsalva ${ }^{19}$.

\section{Monitorización fetal continua ${ }^{19}$ \\ Posparto/puerperio inmediato}

Evitar hemorragia tras el alumbramiento con masaje uterino y administración ev de oxitocina ( $<2$ unidades/minuto para evitar hipotensión). Los análogos de prostaglandina $\mathrm{F}$ son buena alternativa cuando se presenta hemorragia, a menos que se deba evitar el aumento de la presión arterial pulmonar. Evitar metilergometrina por el ries- 
go de vasoconstricción y elevación de TA sistémica en el $10 \%$.

Monitorización hemodinámica de la madre durante 12-24 horas por los cambios hemodinámicos del puerperio, que pueden llevar a fallo cardiaco ${ }^{18}$.

Si precisan reposo prolongado, asociar medidas de prevención de trombosis venosa profunda como medias elásticas y deambulación precoz.

\section{NEUROLOGÍA}

\section{- CEFALEA}

La cefalea es un síntoma común en el embarazo, y requiere un diagnóstico dife- rencial entre cefaleas primarias (cefalea tensional, migraña, cefalea en racimos, histamínica) y las cefaleas secundarias (trombosis venosa cerebral, ACVA, hemorragia subaracnoidea, hipertensión intracraneal, meningitis-encefalitis,tumor cerebral).

\section{Cefaleas primarias}

La más frecuente es la cefalea tensional. Las mujeres con migraña que quedan gestantes presentan mejoría en un $50-80 \%$, y el 5\% empeoran (deben suspender el tratamiento preventivo ${ }^{20}$. Las cefaleas primarias tienen unos criterios clínicos específicos, descritos en Tabla $4^{21}$.

Tabla 4. Criterios clínicos específicos de las cefaleas primarias.

\begin{tabular}{|c|c|c|c|}
\hline Síntomas & Migraña & Cefalea tensional & Cefalea en racimos \\
\hline Localización & $\begin{array}{l}60-70 \% \text { unilateral } \\
30 \% \text { bifrontal o global }\end{array}$ & Bilateral & $\begin{array}{l}\text { Siempre unilateral, } \\
\text { periocular o en sien }\end{array}$ \\
\hline Características & $\begin{array}{l}\text { - Patrón creciente, } \\
\text { pulsátil } \\
\text { - Moderada o severa } \\
\text { - Agravada por actividad } \\
\text { física }\end{array}$ & $\begin{array}{l}\text { Presión o tensión con } \\
\text { altibajos }\end{array}$ & $\begin{array}{l}\text { - Inicio rápido, } \\
\text { alcanzando dolor } \\
\text { máximo en minutos } \\
\text { - Dolor profundo, } \\
\text { continuo y explosivo }\end{array}$ \\
\hline $\begin{array}{l}\text { Apariencia del } \\
\text { paciente }\end{array}$ & $\begin{array}{l}\text { Descanso en habitación } \\
\text { oscura sin ruidos }\end{array}$ & $\begin{array}{l}\text { Puede permanecer } \\
\text { activo o necesitar } \\
\text { descanso }\end{array}$ & Permanece activo \\
\hline Duración & 4 a 72 horas & Variable & De 30 minutos a 3 horas \\
\hline Síntomas asociados & $\begin{array}{l}\text { - Náuseas } \\
\text { - Vómitos, fotofobia } \\
\text { - Fonofobia } \\
\text { - Puede tener aura } \\
\quad \text { (visual, motora) }\end{array}$ & Ninguno & $\begin{array}{l}\text { - Lagrimeo ipsilateral, } \\
\text { ojo rojo y rinorrea } \\
\text { - Palidez } \\
\text { - Sudoración. }\end{array}$ \\
\hline
\end{tabular}

\section{Migraña $^{20}$}

El tratamiento de la migraña lo constituyen:

1. Inicialmente paracetamol $1 \mathrm{~g}$. Si no responden, añadir metoclopramida $10 \mathrm{mg}$, o paracetamol+codeína (30-60 $\mathrm{mg})$, o paracetamol+cafeína (40 mg).

2. AINES, segunda opción en el $1^{\circ}$ y $2^{\underline{o}}$ trimestre, su uso en el $3^{\text {er }}$ trimestre no debe exceder las $48 \mathrm{~h}$ por los riesgos fetales.

3. Opioides: codeína (FDA C, D en uso prolongado o a término), meperidi- na (FDA B, D en uso prolongado o a término), morfina (FDA B, D en uso prolongado o a término).

4. En casos de migraña intratable pueden usarse corticoides (prednisona $20 \mathrm{mg} \mathrm{c} / 6 \mathrm{~h}$ durante dos días o metilprednisolona $4 \mathrm{mg} \mathrm{c} / 8 \mathrm{~h}$ hasta 6 días; riesgo de labio leporino en su uso en $1^{\mathrm{o}}$ trimestre) o droperidol ev $(2,5 \mathrm{mg}$ c/30 minutos hasta 3 dosis, vigilar síntomas extrapiramidales, no descrita teratogenicidad). 
5. Profilaxis: en casos de $>3$ crisis/mes, crisis muy graves que no responden a tto sintomático. Se usan betabloqueantes (atenolol, metoprolol o propanolol 40-120 mg/12h; no teratógenos, pero pueden provocar retraso de crecimiento fetal, bradicardia neonatal transitoria o depresión respiratoria e hiperbilirrubinemia), bloqueantes de los canales del calcio o antidepresivos (amitriptilina, suspenderla 2 semanas antes del parto).

\section{Cefalea tensional}

El tratamiento incluye ${ }^{21}$ :

1. Técnicas de relajación, evitar sueño excesivo, cafeína, alcohol y alimentos ricos en tiamina (quesos curados, chocolate y nueces).

2. Tratamiento médico de elección: paracetamol, con o sin codeína o cafeína. Si no funciona AINES y si no amitriptilina.

3. Cefalea histamínica o en racimos

4. Oxígeno al $100 \%$ a 7 litros/minuto durante 5 minutos y lidocaína intranasal.

5. Evitar siestas y alcohol.

6. $\mathrm{Si}$ aparecen $>3$ al mes, prednisona profiláctica 40-60 mg/día gradual durante 3 semanas.

\section{Cefaleas secundarias $^{20}$}

Si una gestante tiene antecedentes de cefalea no precisa proceso diagnóstico nuevamente a no ser que presente cambios en los síntomas.

Sin embargo, hay algunos signos de alerta que nos hacen investigar la cefalea para descartar preeclampsia o evento neurovascular agudo, como son: aparición repentina y severa, irradiación occípito-nucal, aparición de cefalea por primera vez en el embarazo, dolor de características diferentes a episodios previos, infección previa o coexistente, aparición durante esfuerzo, alteración del estado de consciencia, signos de meningismo, fiebre, déficit neurológico focal, papiledema.

\section{Pruebas diagnósticas ${ }^{20}$}

Hemograma, pruebas de coagulación, función hepática y renal, labstix en orina.
En un segundo tiempo se deben solicitar anticuerpos anticardiolipina y anticoagulante lúpico, así como estudio de trombofilias.

TAC puede hacerse si está indicado sin exposición radiológica dañina para el feto, puesto que un TAC de cabeza o cervical expone al útero a menos de $1 \mathrm{mrad}$ de radiación.

RMN: no expone al feto a radiación ionizante, y puede ser preferible al TAC en caso de patología cráneo-espinal no hemorrágica ni traumática (edema, enfermedad vascular, masa o infección local). Cuando se sospecha lesión vascular arterial puede detectarse con RMN con angiografía con o sin galodinio (el galodinio cruza la barrera placentaria y es excretada por los riñones fetales sin ningún efecto descrito en la literatura, pero dada su limitada experiencia en la embarazada debe evitarse, a menos que los beneficios potenciales justifiquen los riesgos teóricos para el feto). La RMN con venografía es el gold estándar para detectar trombosis venosa y no precisa galodinio.

Punción lumbar: en caso de sospecha de hipertensión intracraneal o infección, debe realizarse antes técnicas de neuroimagen que excluyan lesión ocupante de espacio grande que contraindica la punción lumbar.

EEG: en casos de sospecha de crisis clínicas o subclínicas, alteración o pérdida de consciencia y sospecha de encefalopatía.

El puerperio supone una etapa de riesgo para desarrollo de cefalea, por la deprivación de sueño, cambios hormonales, alimentación irregular, estrés y cansancio. El diagnóstico diferencial en este periodo incluye preeclampsia-eclampsia, cefalea postpunción dural (tratamiento analgésico con reposo en cama a la espera de restauración del líquido cefalorraquídeo y si no funciona parche hemático), migraña y cefalea tensional. Si presenta signos neurológicos focales se debe hacer estudio con neuroimagen y valoración por neurología para descartar tumor hipofisario o trombosis del seno venoso cerebral.

\section{EPILEPSIA $^{21,22}$}

Es la segunda enfermedad neurológica más frecuente del embarazo tras la cefalea. El embarazo en la mujer con epilepsia no 
aumenta el número de crisis, pero sí puede sufrir más crisis por la disminución de los niveles terapéuticos (hiperemesis, uso de antiácidos, inducción de enzimas hepáticas, aumento del filtrado glomerular...) y porque disminuye el umbral para la convulsión. Por ello es recomendado medir los niveles de antiepiléptico en sangre una vez al mes.

El feto se expone al riesgo de los fármacos (defectos del tubo neural por valproato y carbamacepina, malformaciones orofaciales por fenitoína y fenobarbital) y al riesgo de las crisis (hipoxia por dismi- nución del flujo uterino, golpes en la crisis, apnea postcrisis).

Una convulsión se define como un trastrono paroxístico del sistema nervioso central caracterizado por una descarga neuronal anormal con pérdida de la conciencia o no. La epilepsia es una enfermedad caracterizada por la tendencia a dos o más convulsiones recidivantes no provocadas por alguna lesión inmediata conocida. Cuando una gestante se presenta en urgencias por una convulsión se deben definir las características para valorar el tipo de crisis epiléptica (Tabla 5).

Tabla 5. Tipos de crisis epilépticas.

\begin{tabular}{|c|c|c|}
\hline Tipos de crisis & Características & Forma de presentación \\
\hline Convulsivas generalizadas & $\begin{array}{l}\text { - Pérdida de conciencia } \\
\text { - Descarga EEG difusa } \\
\text { - Afectación de ambos hemisferios } \\
\text { - Alteraciones motoras de las } 4 \\
\text { extremidades }\end{array}$ & $\begin{array}{l}\text { - No convulsivas, ausencias atípicas } \\
\text { - Convulsivas, mioclónicas, } \\
\text { clónicas, tónicas, tónico-clónicas, } \\
\text { atónicas }\end{array}$ \\
\hline Convulsiva parcial o focal & $\begin{array}{l}\text { - Rara pérdida de conciencia } \\
\text { - Limitada a un área cerebral } \\
\text { - Combinación de síntomas } \\
\text { motores, sensitivos, sensoriales, } \\
\text { psíquicos, vegetativos }\end{array}$ & $\begin{array}{l}\text { - Convulsiones parciales simples } \\
\text { - Convulsiones parciales complejas } \\
\text { - Convulsiones parciales que } \\
\text { evolucionan a generalizadas }\end{array}$ \\
\hline Crisis psicógena & $\begin{array}{l}\text { Comienzo gradual, con aura } \\
\text { prolongada, sin confusión } \\
\text { postcrítica, mantiene memoria } \\
\text { detallada durante la crisis }\end{array}$ & - Convulsiones tónico-clónicas \\
\hline
\end{tabular}

\section{Diagnóstico}

Inicialmente realizar historia clínica, incluyendo toma de anticonvulsivantes, valorar el tipo de crisis, hemograma, glucemia, electrolitos, calcio, magnesio, sustancias tóxicas y nivel de anticonvulsivante.

Es preciso realizar el diagnóstico diferencial de una convulsión por exclu- sión, utilizando los métodos diagnósticos como RMN y TAC como en la no embarazada (excepto con la limitación en utilización de radiaciones ionizantes), así como la punción lumbar. Las causas de las convulsiones en el embarazo y postparto se resumen en el siguiente cuadro (Tabla 6).

Tabla 6. Causas de las convulsiones en el embarazo.

\begin{tabular}{ll}
\hline 1. Epilepsia idiopática & - Infarto cerebral \\
2. Epilepsia secundaria a causa específica & - Hemorragia subaracnoidea o hemorragia cerebral \\
- Trauma & - Encefalopatía hipertensiva \\
- SAF & - Trombosis venosa cerebral \\
- Masa intracraneal & 5. Metabólica \\
- Epilepsia gestacional & - Hiponatremia, hipoglucemia, hipocalcemia \\
3. Infección intracraneal & - Fallo renal o hepático \\
- Meningitis & • Anoxia \\
- Encefalitis & - Abstinencia de alcohol \\
- Absceso cerebral/empiema subdural & 6. Toxicidad por drogas: anestésicos locales, antide- \\
- Malaria cerebral & presivos tricíclicos, anfetaminas, litio. \\
4. Enfermedad vascular & 7. Pseudoepilépsica-síndrome de conversión \\
- Eclampsia &
\end{tabular}




\section{Tratamiento}

Inicialmente más importante que detener la convulsión es asegurar la oxigenación materna y evitar el riesgo de aspiración:

1. Vía aérea permeable

2. Oxígeno al $30 \%$ a 6 litros $/ \mathrm{min}$.

3. Aspiración de secreciones laríngeas.

4. Posteriormente iniciar terapia anticonvulsivante, de elección loracepan o clonacepan (Rivotrilß). Las pautas de tratamiento son similares a las de la no gestante en el control inicial. El sulfato de magnesio no es una alternativa apropiada para la crisis epiléptica, pero cuando la crisis se presenta inicialmente en el tercer trimestre o en el periodo postparto puede ser difícil distinguirlo de eclampsia y en esos casos se debe tratar como si fuese eclampsia mientras se estudian otras causas.

Es importante descartar que no nos encontrarnos ante un status epiléptico, que es la situación en la que aparecen convulsiones sin restablecerse totalmente entre una y otra convulsión durante más de 30 minutos, cuando la convulsión dura más de 10 minutos o se producen dos convulsiones sin recuperar la conciencia entre ambas. Durante las convulsiones aparecen hipertensión, taquicardia, hipoxia y acidosis láctica. Las contracciones musculares pueden producir rabdomiolisis, hipertermia y necrosis tubular aguda mioglobinúrica. Si persiste durante más de dos horas, puede aparecer disfunción neurológica permanente. En ese caso hay que suministrar:

1. $50 \mathrm{ml}$ de glucosado al $50 \%$ y $100 \mathrm{mg}$ de tiamina ev

2. Diacepan $10 \mathrm{mg}$ ev en 2 minutos y continuar con $2 \mathrm{mg} / \mathrm{min}$ hasta que cesen las convulsiones.

3. Fenilhidantoína $50 \mathrm{mg} / \mathrm{min}$ en solución salina.

4. Si persiste actividad convulsiva, intubación endotraqueal y fenobarbital ev $50 \mathrm{mg} / \mathrm{min}$ hasta dosis total de 20 $\mathrm{mg} / \mathrm{kg}$. Si fracasa, anestesia general.

5. Valorar estado fetal: ecografía, CTG.

6. Valorar del estado neurológico.
El status epiléptico tiene una tasa de mortalidad del $25 \%$ en gestantes con $50 \%$ de pérdida fetal.

\section{ACCIDENTES CEREBROVASCULARES ${ }^{21,23}$}

Los accidentes cerebrovasculares (ACV) se clasifican en isquémicos (arterial y venoso), y hemorrágicos (subaracnoideo e intracerebral $)^{21,23}$. Se dan el $10 \%$ en el embarazo, $40 \%$ en el parto y $50 \%$ en el puerperio. Las causas de ACV asociados al embarazo son diferentes a la población general, siendo la preeclampsia/eclampsia la causa más frecuente (Tabla 7).

Tabla 7. Causas de los accidentes cerebrovasculares.

\begin{tabular}{|l|l|}
\hline \multicolumn{1}{|c|}{ Isquémicos } & \multicolumn{1}{c|}{ Hemorrágicos } \\
\hline - Preeclampsia/ & - Preeclampsia/ \\
eclampsia & eclampsia \\
- Vasculopatía primaria & - CID \\
del SNC & - Malformación \\
- Disección de la arteria & arteriovenosa \\
carótida & - Ruptura de aneurisma \\
- Embolia cardiaca & - Abuso de cocaína \\
- Coagulopatías & - Vasculopatía primaria \\
(trombofilias, SAF) & SCN \\
- Púrpura trombótica & - Vasculitis por \\
trombocitopénica & sarcoidosis \\
- Vasculitis & \\
postherpética & \\
\hline
\end{tabular}

El proceso diagnóstico en un ataque cerebral en la embarazada es similar al que se realiza en la población general.

- Estudio por imagen inicial con TAC sin contraste, aunque la RMN es más segura en el embarazo y puede ser más sensible para el diagnóstico de infarto en fases iniciales. Se deben evitar los contrastes si es posible y el abdomen protegido en caso de TAC.

- Ecocardiografía y estudio Doppler de carótidas si la clínica lo sugiere.

- ECG, hemograma, perfil metabólico, perfil lipídico, VIH, drogas en orina, y ANA.

- Pequeñas hemorragias subaracnoideas pueden escaparse a la detección 
de RMN y TAC, especialmente si pasa tiempo de la hemorragia al estudio. En estas pacientes puede ser útil la realización de punción lumbar.

- Punción lumbar para excluir infección cuando haya signos meníngeos.

- Con posterioridad estudio de trombofilia congénita o adquirida cuando se detecte un evento neurológico isquémico no hemorrágico en el embarazo.

\section{Trombosis venosa cerebral}

Es un ACV isquémico que se presenta generalmente en el puerperio inmediato. Esta favorecido por trombofilias, hipertensión, infección o cesárea.

Se presenta con cefalea (suele preceder al resto de síntomas, es difusa y a menudo intensa), vómitos, crisis parcial o generalizada, confusión, visión borrosa, déficits neurológicos focales y alteración del estado de conciencia.

Para confirmar el diagnóstico es preciso hacer RMN.

El tratamiento debe iniciarse tan pronto como se confirma el diagnóstico, y consiste en revertir la causa cuando es conocida, controlar las convulsiones y la hipertensión intracraneal, y el uso de anticoagulantes. Cuando no funciona la anticoagulación puede estar indicada la trombolisis local.

\section{Trombosis arterial cerebral}

Este accidente vascular isquémico tiene relación con ateroesclerosis y con anticuerpos antifosfolípidos positivos, así como con patología cardiaca reumática con o sin asociación con arritmias (fibrilación auricular) en $3^{\text {er }}$ trimestre o puerperio.

\section{Clínica}

Cefalea intensa súbita, déficits neurológicos y/o convulsiones. Según el territorio vascular afectado:

\section{Arteria carótida interna:}

- Arteria cerebral media: hemiparesia con afectación facial, y trastrono sensorial ipsilateral, hemianopsia homónima, Si se afecta el hemisferio dominante (generalmente el izquierdo) hay afasia y disfasia.

- Arteria cerebral anterior: hemiplejia sensitivomotora con predominio del miembro inferior contralateral asociado con frecuencia a incontinencia urinaria.

2. Arteria basilar:

- Arteria cerebral posterior: alteración hemisensorial contralateral y pérdida visual contralateral.

- Arteria cerebelosa posteroinferior (síndrome de Wallenberg): defecto sensorial facial, síndrome de Horner ipsilateral, dolor y aumento de temperatura, ataxia cerebelosa, nistagmo, disfagia, disartria, náuseas, vómitos, hipo y preservación motora.

- Síndromes del tronco cerebral: afectación ipsilateral de pares craneales, hemiparesia contralateral, nistagmo y alteración de la conciencia.

\section{Diagnóstico}

TAC craneal sin contraste, RMN o angiografía, ecocardiograma, ecografía modo B o Doppler pulsátil de arterias carótidas.

\section{Tratamiento}

- Analgesia, AAS, HBPM, o activador tisular del plasma (riesgo de hemorragia puerperal si se administra $<8$ horas preparto).

- Endarterectomía carotídea si hay émbolo en la bifurcación carotídea.

\section{ACV HEMORRÁGICAS}

\section{Hemorragia intracraneal}

Es un ACV hemorrágico originado por complicaciones de la hipertensión (HTA crónica, Hipertensión inducida del embarazo, preeclampsia), o por uso de cocaína. Tiene alta tasa de mortalidad y alto riesgo de secuelas neurológicas permanentes. Es muy importante la prevención. 


\section{Hemorragia subaracnoidea}

ACV hemorrágico que causa el $10 \%$ de las muertes en el embarazo y parto. Tiene relación con rotura de aneurismas o malformaciones arteriovenosas. El periodo de mayor riesgo de ruptura es el $3^{\text {er }}$ trimestre y el postparto inmediato.

\section{Clínica}

Irritabilidad meníngea (cefalea intensa, rigidez de cuello, náuseas y vómitos), taquicardia, fiebre leve, HTA, leucocitosis, proteinuria. Puede evolucionar a obnubilación, con-vulsiones y coma.

\section{Diagnóstico}

TAC, más útil que la RMN en las primeras 24 horas. Punción lumbar ante sospecha clínica y TAC normal. Angiografía.

\section{Tratamiento}

Es recomendable tratamiento ante el alto riesgo de resangrado, siendo las técnicas de neurocirugía seguras en el embarazo. La mayoría de los neurocirujanos prefieren operar en las primeras $48 \mathrm{~h}$. Si es $<32$ semanas, algunos autores recomiendan extracción fetal previa, y si no es posible por prematuridad extrema, control estricto de la hipotensión y la recuperación de la hipotermia en que se realizan éste tipo de intervenciones.

Puede usarse nimodipino para reducir el vasoespasmo y es importante el control de la HTA.

\section{Vía de parto}

Las mujeres a las que se ha tratado la causa de la hemorragia (clampaje de aneurisma, excisión de malformación arteriovenosa) pueden optar al parto vaginal, siendo controvertido en el caso de las que no han sido tratadas definitivamente. Así en éstas las alternativas son cesárea profiláctiva o anestesia regional y parto instrumental para eliminar las fluctuaciones hemodinámicas asociadas al dolor y las maniobras de valsalva. No hay datos de largas series o randomizados, pero parece haber las mismas tasas de mortalidad materno fetal con ambos métodos, reservando así la cesárea a indicaciones obstétricas. Además la cesárea no es completamente protectora, pues se ha descrito rotura de aneurismas en cesáreas electivas. Con independencia de la vía de parto es importante controlar la hipertensión y minimizar las fluctuaciones de la presión sanguínea.

El estado clínico de la madre influye a la hora de elegir la vía de parto, siendo recomendable la cesárea en la gestante en coma. La anestesia epidural puede ser utilizada si no hay evidencia de aumento de la presión intracraneal.

\section{PARÁLISIS DE BELL ${ }^{24}$}

Se define como la parálisis del nervio facial; típicamente afecta a las tres ramas periféricas, provocando una expresión facial asimétrica y ptosis palpebral, pérdida de secreción lacrimal, salivar y pérdida del gusto en los 2/3 anteriores de la lengua.

Hay un aumento de la prevalencia de 2 a 4 veces durante el embarazo, especialmente en el tercer trimestre y en la primera semana postparto. No está claro el motivo, en parte porque el mecanismo de la parálisis de Bell no se conoce claramente.

\section{Tratamiento}

Similar a la no embarazada con oculsión ocular y lubricación artificial, así como prednisona $60-80 \mathrm{mg} /$ día + valaciclovir 1 $\mathrm{g} / 8 \mathrm{~h}$, excepto por el riesgo de los corticoides en las primeras 9 semanas (fallo en el cierre del paladar).

\section{Complicaciones}

Parece haber una asociación entre parálisis de Bell y preeclampsia. Además es más frecuente la parálisis completa (65 vs $50 \%$ en población general), lo cual implica además en las gestantes menor probabilidad para recuperar la función satisfactoriamente (52 vs $77-88 \%$ ); en parte puede ser debido a que es menos probable que reciban tratamiento.

\section{SÍNDROME DEL TÚNEL CARPIANO ${ }^{21}$}

Se refiere a las parestesias, dolor u hormigueo en el pulgar, índice y dedo medio 
de la mano, que resulta de la compresión del nervio mediano en el tunel carpiano. Generalmente se despiertan con entumecimiento, quemazón y pinchazos en la zona de inervación del mediano, bilateral en el $75 \%$ de los casos. A menudo los pacientes sacuden la mano para aliviar el dolor.

Incidencia en el embarazo del 2-35\%, aumentada por la retención hídrica del embarazo y los cambios hormonales. Generalmente se produce en el $3^{\text {er }}$ trimestre, y en la mayoría se resuelve en las semanas o meses después del parto.

\section{Tratamiento}

Puede ser beneficioso fijar la muñeca por la noche en una posición neutra o en ligera extensión. La inyección de corticoides o la cirugía se precisa rara vez en el embarazo.

\section{DERMATOPATÍAS}

Las alteraciones dermatológicas durante la gestación incluyen desde cambios fisiológicos hasta enfermedades dermatológicas propias del embarazo, pasando por el grupo de enfermedades dermatológicas que pueden sufrir cambios en el embara$\mathrm{zO}^{25}$.

Los motivos de consulta a urgencias suelen ser la erupción cutánea, el prurito intenso o el dolor o escozor que acompaña a las lesiones.

Alguna de estas dermatopatías implican riesgo materno fetal por lo que debe realizarse una valoración adecuada de cada cuadro.

Es preciso conocer los cambios fisiológicos, que incluyen ${ }^{26}$ :

1. Hiperpigmentación en el $90 \%$ de las gestantes en algún momento del embarazo. Cloasma o melasma en el $50-60 \%$, localizado en regiones malares y frente, que se agrava con el sol.

2. Cambios vasculares: edemas, varicosidades, eritema plantar, arañas vasculares, cutis marmorata (coloración violácea moteada de la piel de las piernas cuando se exponen al frío), púrpuras y petequias espontáneas, hipertrofia gingival, épulis y hemangiomas en cuello y manos.

3. Cambios estructurales: estrías (en el $90 \%$, localizadas en nalgas y abdomen), molusco fibroso gestacional (fibromas cutáneos en cuello y axilas de hasta $5 \mathrm{~mm}$ sin potencial maligno que pueden involucionar o no tras el parto).

4. Cambios en glándulas y anejos cutáneos: alopecia telógena postparto (difusa, suele durar 3 meses, sólo requiere apoyo emocional), hirsutismo y acné, aumento del crecimiento $\mathrm{y}$ fragilidad ungueal, depresiones lineales transversales en las uñas.

Las enfermedades dermatológicas propias del embarazo podemos clasificarlas según presenten o no riesgo maternofetal.

\section{Sin riesgo materno-fetal}

Prúrigo gestacional ${ }^{25,27}$

- 1/300-450 embarazos. De etiopatogenia desconocida, aparece en las últimas semanas del $2^{\circ}$ trimestre.

- Lesiones: pápulas excoriadas y con costras de 1-2 mm, en grupos, en superficies extensoras, muy pruriginosas.

- Anatomía patológica: patrón inespecífico.

- Tratamiento: corticoides tópicos o antihistamínicos orales, emolientes.

- Desaparecen tras el parto, pueden dejar lesiones pigmentadas residuales.

\section{Pápulas y placas urticariformes pruriginosas o erupción polimorfa del embarazo ${ }^{25,27}$}

- Es la dermatosis más frecuente del embarazo, en 1-160/300, el 75\% primigestas. Aparece en el $3^{\text {er }}$ trimestre.

- Lesiones inicialmente en abdomen en las estrías, pápulas eritematosas rodeadas de halo pálido fino, desde donde se extienden a brazos, nalgas y muslos, respetando cara y palmas; muy pruriginosas.

- Anatomía patológica: patrón inespecífico. 
- Tratamiento: antihistamínicos orales y corticoides tópicos, ocasionalmente prednisona oral.

- Se resuelve espontáneamente en periodo neonatal (rara vez más allá de la primera semana).

\section{Foliculitis pruriginosa del embarazo $0^{25,27}$}

- Incidecia desconocida. Aparece en el $2^{\mathrm{o}}$ y $3^{\text {er }}$ trimestre.

- Lesiones: pápulas eritematosas y pústulas foliculares pruriginosas en abdomen, tronco y extremidades.

- Anatomía patológica: infiltrado linfohistiocítico perivascular o intersticial, con excoriación de la epidermis, similar a la erupción polimorfa del embarazo. Inmunofluorescencia negativa.

- Pronóstico: resolución tras el parto.

- Tratamiento: hidrocortisona 1\%, peróxido de benzoilo al 5-10\% y UVB.

\section{Con riesgo materno-fetal}

\section{Herpes gestacional o penfigoide gestacional $^{25,27}$}

- 1/10.000-50.000 embarazos. Etiología autoinmune. Inicio en $2^{\mathrm{o}}-3^{\text {er }}$ trimestre.

- Lesiones: erupción polimorfa (pápulas, placas, vesículas y ampollas) pruriginosa con escozor y dolor, inicialmente periumbilical, que se extienden por abdomen, nalgas, antebrazos, palmas y plantas, el prurito puede preceder a las lesiones.

- Anatomía patológica: edema subepidérmico con infriltración de eosinógilos, con inmunofluorescencia directa que muestra depósitos de C3 en la membrana basal (patognomónico).

- Pronóstico materno: exacerbaciones y remisiones en el embarazo (75\% postparto). No deja cicatriz y puede recidivar en embarazos posteriores, con anovulatorios o con menstruación.

- Pronóstico fetal: aumento de parto pretérmino y bajo peso. El 5-10\% lesión al nacer similar y autolimitada de semanas.
- Tratamiento: antihistamínicos orales y corticoides tópicos inicialmente, casos severos precisan corticoides orales a dosis $0,5 \mathrm{mg} / \mathrm{kg} /$ día de prednisona. Vigilar sobreinfección bacteriana.

\section{Colestasis intrahepática del embarazo}

Aunque no suponga en sí una dermopatía, sino que la afectación dérmica, es un síntoma secundario, algunos autores la clasifican así.

\section{Impétigo herpetiforme o psoriasis pustular $^{25,27,28}$}

Es una posible reactivación o la presentación inicial de psoriasis en personas predispuestas.

Lesiones: placas eritematosas sin prurito, con márgenes pustulares y distribución en pliegues sin afectar cara, manos y pies, dolorosas al tacto; les precede malestar general y espasmos musculares con fiebre, náuseas y vómitos.

Analítica: leucocitosis, posible hipocalcemia, hipofosfatemia, hipoalbuminemia e insuficiencia renal y hepática.

Anatomía patológica: colecciones de neutrófilos en el estrato espinoso y córneo. Epidermis con espongiosis, paraqueratosis e hiperplasia psriasiforme.

Pronóstico: Resolución del cuadro tras el parto. Suele recidivar en otros embarazos. Puede provocar muerte fetal intrauterina y disfunción placentaria.

Tratamiento: soporte con reposición de líquidos y electrolitos. Corticoides sistémicos con prednisolona $0,5-1 \mathrm{mg} / \mathrm{kg} /$ día. Asociar ciclosporina si no mejora (FDA C). Antibióticos si hay sobreinfección. Control estricto fetal.

\section{BIBLIOGRAFÍA}

1. FunaI E.F. Hyperemesis gravidarum. UpToDate. 2008.

2. Maldonado MD, Crespo A, González de Merlo G. Hiperemesis gravídica. Madrid 2007: 57-65. En: Cañete Palomo ML, Cabero Roura L. Urgencias en Ginecología y Obstetricia: aproximación a la medicina basada en la evidencia. 
3. Lombardía J, FernÁndez M. Ginecología y Obstetricia. Manual de consulta rápida. Patología obstétrica. Madrid: Editorial Panamericana, 2007: 348-353.

4. Wanke Ch.A. Aproach to the adult with acute diarrhea in developed countries. UpToDate 2008.

5. NúÑEz Isabel S, MainKa J. Diarrea. En: Problemas de salud en el embarazo ( $2^{\text {a }}$ edición). Madrid 2002: 225-227.

6. BiAnco A. Maternal gastrointestinal tract adaptation to pregnancy. UpToDate 2008.

7. Barth WH, GoldBerg JE. Appendicitis in pregnancy. UpToDate 2008.

8. Guzman A. Dolor abdominal en el embarazo. En: Cañete Palomo ML, Cabero Roura L. Urgencias en Ginecología y Obstetricia: aproximación a la medicina basada en la evidencia. Madrid 2007: 257-271.

9. Metola Gómez M, Martín Blázquez M. Hepatopatías en el embarazo. En: Problemas de salud en el embarazo ( $2^{a}$ edición). Madrid 2002: 236-246.

10. BACQ Y. Aproach to liver disease ocurring during pregnancy. UpToDate 2008.

11. BACQ Y. Intercurrent hepatobiliary disease during pregnancy. UpToDate 2008.

12. Lombardía J, Fernández M. Ginecología y Obstetricia. Manual de consulta rápida. Patología obstétrica. Madrid: Editorial Panamericana, 2007: 454-462.

13. Avila SÁnchez MJ. Varices y pesadez. En López de Castro F. y Lombardía Prieto J. Problemas de salud en el embarazo. Manual para médicos de atención primaria. Madrid 2002: 154-157.

14. Grañeras A, Hernández JM. Enfermedad tromboembólica y gestación. En: Urgencias en Ginecología y Obstetricia: Aproximación a la Medicina basada en la evidencia. Cañete ML, Cabero L. Madrid 2007: 225-242.

15. DeCara JM, Lang RM, Foley MR. Management of heart failure in pregnancy. UpToDate 2008 .
16. PRODID PJ. Arrythmias and conduction disturbances associated with pregnancy. UpToDate 2008 .

17. Arnedo S, Barciela R. Enfermedades cardiovasculares en el embarazo. Urgencias en Ginecología y Obstetricia: aproximación a la medicina basada en la evidencia. Madrid 2007: 409-424.

18. S.E.G.O. Cardiopatías y embarazo. Protocolos asistenciales en Ginecología y Obstetricia. 2008.

19. Waksmonski CA, LaSAla A., Foley MR Acquired heart disease and pregnancy. UpToDate 2008.

20. Lee ML, Guinn D, Hickenbottom S. Headache in pregnancy. UpToDate 2008

21. Diaz-Plaza I, Rustarazo I. Trastornos neurológicos en el embarazo. En: Cañete Palomo ML, Cabero Roura L. Urgencias en Ginecología y Obstetricia: aproximación a la medicina basada en la evidencia. Madrid 2007: 357-380.

22. Schachter S. Mangement of epilepsy and pregnancy. UpToDate 2008.

23. Kutcher J, Lee M-L, Hickenbottom S. Cerebrovascular disorders complicating pregnancy. UpToDate 2008.

24. Kutcher J, Lee M-L, Hickenbottom S. Neurologic disorders complicating pregnancy. UpToDate 2008.

25. Keltz Pomeranz M. Dermatoses of pregnancy. UpToDate 2008.

26. Arevalillo Fernández N, Mellado Muñoz AM Alteraciones dermatológicas. En: Problemas de salud en el embarazo ( $2^{\mathrm{a}}$ edición). Madrid 2002: 134-140.

27. Palacios A, Maldonado MD, García Almagro D. Problemas dermatológicos en la gestación. En: Cañete Palomo ML, Cabero Roura L. Urgencias en Ginecología y Obstetricia: aproximación a la medicina basada en la evidencia. Madrid 2007: 381-392.

28. Luesley D, BAKer P. Antenatal complications: maternal. En: Obstetrics and Gynaecology an evidence-based text for MRCOG. London 2004: 116-119. 
